\title{
Pityriasis rosea and discoid eczema: dose related reactions to treatment with gold
}

\author{
S M Wilkinson, A G Smith, M J Davis, D Mattey, P T Dawes
}

\begin{abstract}
Sixteen cases of either a pityriasiform or discoid eczematous rash occurring in patients with rheumatoid arthritis receiving treatment with gold (sodium aurothiomalate and auranofin) were studied. The results suggest that this is a dose related, not allergic, reaction to gold. The development of this rash is not an absolute indication to stop treatment with gold. Control can often be effected with potent topical steroids or a reduction in the dose or frequency of treatment with gold.
\end{abstract}

(Ann Rheum Dis 1992; 51: 881-884)

The treatment of rheumatoid arthritis with gold results in adverse reactions in about $30 \%$ of patients, of which most are cutaneous, ${ }^{1}$ often necessitating the discontinuation of treatment. A pityriasis rosea-like eruption is recognised to occur as a consequence of treatment with sodium aurothiomalate. ${ }^{2}$ The mechanism of this reaction is uncertain although eosinophilia ${ }^{3}$ and increased levels of $\mathrm{IgE}^{4}$ have been reported to be associated with and predict the development of toxicity from gold. A pityriasiform rash has also been reported after treatment with captopril $^{5}$ and is thought to result from a toxic dose dependent reaction.

We have studied pityriasiform and discoid eczematous reactions occurring in patients with rheumatoid arthritis and report here the conditions associated with the development of a rash and its subsequent course.

\section{Patients and methods}

All patients seen in a rheumatology drug monitoring clinic over a period of 18 months who developed a suspected cutaneous reaction to drugs used to treat their rheumatoid arthritis were reviewed in a dermatology clinic. Where possible a specific dermatological diagnosis was made and in all patients, where consent was given, a skin biopsy sample was taken for studies of histology and immunofluorescence, together with blood for a full and differential

Table 1 Demographic details of patients developing pityriasiform and discoid eczematous rashes

\begin{tabular}{lllll}
\hline & $\begin{array}{l}\text { Mean }(S D) \\
\text { age (years) }\end{array}$ & $\begin{array}{l}\text { Male:female } \\
\text { ratio }\end{array}$ & $\begin{array}{l}\text { No of } \\
\text { seropositive } \\
\text { patients }\end{array}$ & $\begin{array}{l}\text { Mean (SD) time } \\
\text { to onset (months) }\end{array}$ \\
\hline Pityriasis rosea $(\mathrm{n}=8)$ & $\begin{array}{l}54 \cdot 4(18 \cdot 0) \\
\text { Discoid eczema }(\mathrm{n}=8)\end{array}$ & $1: 1$ & 6 & $\begin{array}{r}5 \cdot 5(8 \cdot 4) \\
11 \cdot 2(6 \cdot 3)^{*}\end{array}$ \\
\hline
\end{tabular}

${ }^{*}$ Excluding three patients with a recent increase in gold dose. blood count, determination of the erythrocyte sedimentation rate and $C$ reactive protein, biochemical profile, and immunoglobulins including IgE. Fifteen control subjects matched for age, sex, and duration of treatment with gold were included in the study.

In some patients patch and prick tests with a $2 \%$ solution of aurothiomalate, intradermal tests with $1 \mathrm{mg}$ aurothiomalate, and lymphocyte proliferation assays were performed. For the lymphocyte proliferation assay, peripheral blood mononuclear cells were obtained by Histopaque-1077 (Sigma Diagnostics) centrifugation of venous blood. Cells were suspended in RPMI 1640 medium containing $10 \%$ fetal calf serum, $1 \mathrm{mM}$ glutamine, and penicillin, streptomycin, and fungizone (complete medium). The cells were seeded into 96 well plates at a density of $1.5 \times 10^{5}$ cells/well with sodium aurothiomalate to achieve final concentrations of $20,40,80$, and $160 \mu \mathrm{g} / \mathrm{ml}$. The volume was made up to $200 \mu \mathrm{l}$ with complete medium. Cultures were performed in triplicate with phytohaemagglutinin at a dilution of 1:200 and no added gold as controls. Following five days of culture, the wells were pulsed with $37 \mathrm{kBq}\left[{ }^{3} \mathrm{H}\right]$ thymidine, the cells being harvested 48 hours later. The washed cells were collected into $10 \mathrm{ml}$ scintillation fluid and counted.

\section{Results}

Over a period of 18 months, 84 patients ( $12 \cdot 1 \%)$ were seen from a total of 695 patients who were attending clinics for monitoring of their treatment with second line drugs. A higher percentage, $21 \cdot 7 \%$ (46), of the patients being treated with gold (173 receiving aurothiomalate and 39 receiving auranofin) was seen.

Table 1 summarises the main demographic details. Eight patients were seen with a pityriasiform eruption (fig l) with isolated lesions on the limbs or an eruption resembling pityriasis rosea with multiple lesions on the trunk. A further nine patients were seen with lesions typical of discoid eczema (fig 2), usually on the limbs. Of these 17, all but one patient, who was receiving chloroquine, were being treated with gold (12 with aurothiomalate and four with auranofin). There was no relation to the type of non-steroidal anti-inflammatory drug being used. The mean (SD) age at onset of the rash was $55(15.5)$ years and the patients consisted of 11 women and five men of whom 12 were seropositive with a disease duration of $9 \cdot 8(8 \cdot 4)$ years. The time from the start of treatment to the onset of the eruption was $5.5(2 \cdot 8)$ months for the pityriasiform rash and $11 \cdot 2(6 \cdot 3)$ months 


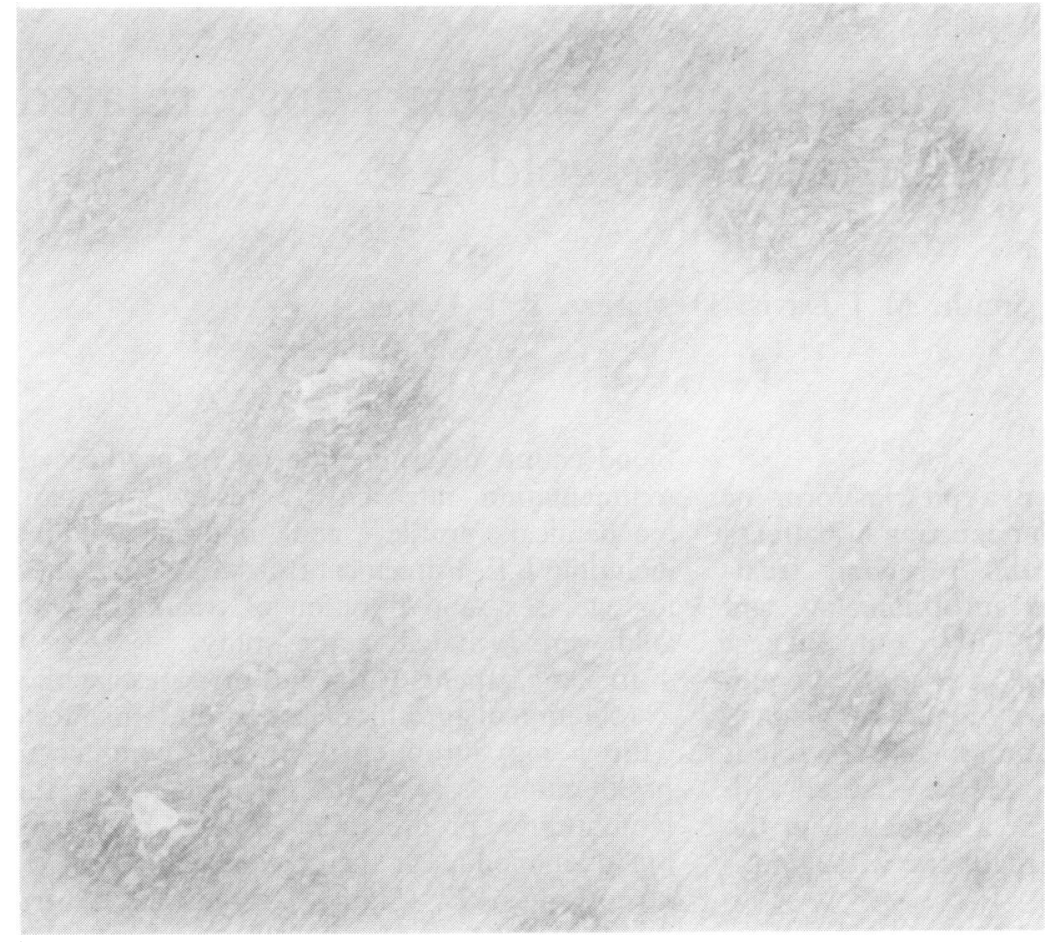

Figure 1 Multiple lesions of pityriasis rosea on the trunk with erythema and peripheral scale.

for discoid eczema (excluding those with a recent increase in dose).

A recent (within four months) increase in the dose of gold or frequency of administration occurred in three of four patients in whom discoid eczema developed after 12 months. The normal dose regimen consisted of $50 \mathrm{mg}$ weekly for 20 weeks, $50 \mathrm{mg}$ fortnightly for 20 weeks, and then $50 \mathrm{mg}$ monthly. Variations in dose occurred in the event of disease relapse or drug toxicity.

Four patients had a previous cutaneous adverse reaction with other drugs used to treat their arthritis; three had reactions to penicillamine, one of which was drug induced pemphigus, and one had a photosensitivity reaction to naproxen.

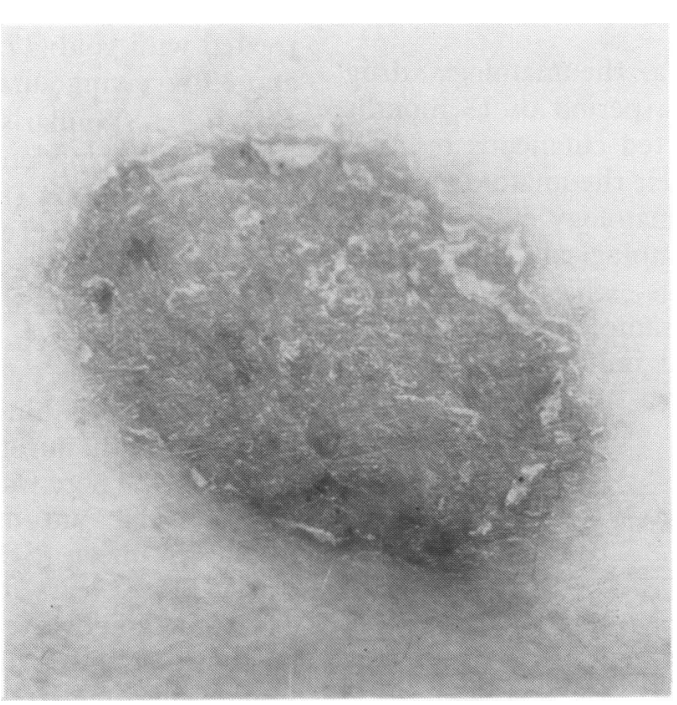

Figure 2 Single lesion of discoid eczema showing erythema and diffuse scale.
The histology of the lesions in five patients with pityriasis rosea and five patients with discoid eczema confirmed the clinical impression. Pityriasiform reactions showed a mild superficial perivascular lymphocytic infiltrate with focal spongiosis and parakeratosis of the epidermis. Discoid eczemas showed superficial perivascular lymphocytic infiltrates with spongiosis and vesicle formation. There was often diffuse parakeratosis with the formation of scale crust. Immunofluorescence was usually negative but in four patients showed granular deposition of $\operatorname{IgM}$, occasionally with $\mathrm{C} 3$, at the basement membrane. Table 2 summarises the results of blood tests and table 3 gives the comparable results in 15 control subjects. Despite the rash, the patient and doctor wished to continue gold treatment because of the clinical improvement in the arthritis.

In six patients (three with pityriasis rosea, three with discoid eczema) gold treatment (all but one treated with aurothiomalate) was discontinued with resolution of the rash. The resumption of treatment in four patients resulted in a recurrence in three (one pityriasis rosea receiving auranofin, two with discoid eczema), confirming the relation to gold. The lack of recurrence in one patient and the occurrence at a time when the patients were likely to have a maximum load of gold suggested that the rash might be dose related rather than occurring through an allergic mechanism.

In the three patients in whom the rash recurred and in the next 10 patients who developed a similar eruption, gold treatment was continued and the rash was treated with topical betamethasone valerate ointment, with resolution in seven patients, or, in addition, a reduction in the dose or frequency of gold treatment, with resolution in three patients. In three patients gold was discontinued because of persisting symptoms. In no patient did a generalised erythroderma develop.

Table 2 Comparison of haematological variables before and after the development of gold toxicity. Results given as mean $(S D)$ values

\begin{tabular}{|c|c|c|}
\hline Haematological variable & $\begin{array}{l}\text { Before rash } \\
(n=16)\end{array}$ & $\begin{array}{l}\text { With rash } \\
(n=16)\end{array}$ \\
\hline $\begin{array}{l}\text { Erythrocyte sedimentation } \\
\text { rate (mm/h) } \\
\text { C reactive protein (mg/l) } \\
\text { Eosinophils } \\
\text { Total IgE }(\mathrm{kU} / \mathrm{l})\end{array}$ & $\begin{array}{c}32 \cdot 4(23 \cdot 0) \\
26 \cdot 8(27 \cdot 1) \\
0.15(0 \cdot 11)\end{array}$ & $\begin{array}{c}19 \cdot 3(15 \cdot 7)^{*} \\
9 \cdot 2(12 \cdot 1)^{:} \\
0 \cdot 16(0 \cdot 17) \dagger \\
18 \cdot 1(20 \cdot 7) \ddagger\end{array}$ \\
\hline
\end{tabular}

Table 3 Comparison of haematological variables in patients and control subjects with the same duration of treatment. Results given as mean $(S D)$ values

\begin{tabular}{lcc}
\hline Haematological variable & $\begin{array}{l}\text { With rash } \\
(\boldsymbol{n}=16)\end{array}$ & $\begin{array}{l}\text { Controls } \\
(\boldsymbol{n}=15)\end{array}$ \\
\hline Erythrocyte sedimentation & $19 \cdot 3(15 \cdot 7)$ & $34 \cdot 3(23 \cdot 7)^{*}$ \\
rate $(\mathrm{mm} / \mathrm{h})$ & $9 \cdot 2(12 \cdot 1)$ & $25 \cdot 8(26 \cdot 4)^{*}$ \\
C reactive protein $(\mathrm{mg} / \mathrm{l})$ & $0 \cdot 16(0 \cdot 17)$ & $0 \cdot 13(0 \cdot 09) \dagger$ \\
Eosinophils & & \\
\hline$p<0 \cdot 05$. & & \\
tNot significant. &
\end{tabular}




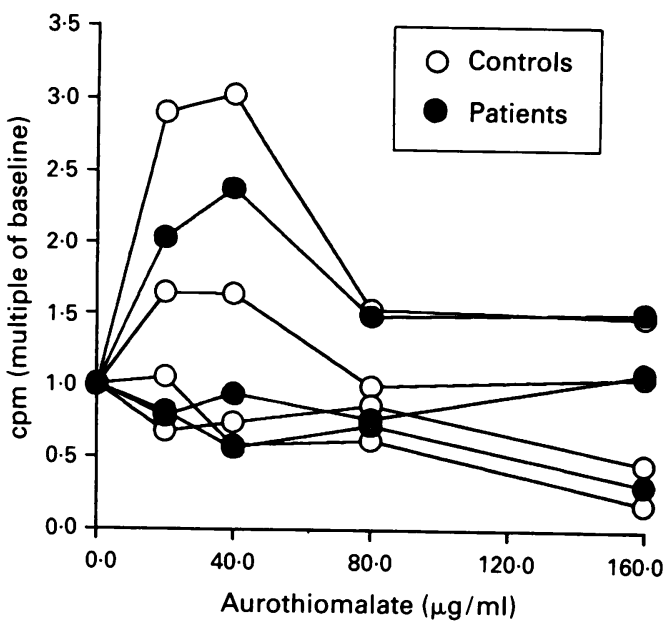

Figure 3 Comparison of lymphocyte proliferation with gold dose in patients and control subjects.

The results of patch tests and prick tests in two patients with pityriasis rosea and one with discoid eczema were negative at 30 minutes as were the intradermal tests at 30 minutes and 48 hours. Figure 3 summarises the results of the lymphocyte proliferation assays. The control subjects were four patients without rheumatoid arthritis who had not received gold. The results of stimulation with phytohaemagglutinin were on average 53 times the basal values in patients and 26 times the basal values in control subjects. At several concentrations of gold there was no difference between the patients and control subjects. It is generally assumed that an increase over basal values of two to three times denotes a positive response in a lymphocyte proliferation assay. In our patients there was a proliferative response at lower concentrations of gold (20-40 $\mu \mathrm{g} / \mathrm{ml}$ ) which was present in both patients and control subjects, implying that this was a nonspecific response and not indicative of an immunological reaction. At higher concentrations $(160 \mu \mathrm{g} / \mathrm{ml})$ a toxic effect on lymphocytes was seen with a low uptake of tritiated thymidine associated with cell death.

\section{Discussion}

All but one of the patients seen with a pityriasiform or discoid eczematous reaction were receiving treatment with gold. This suggests a relation with gold rather than the coincidental occurrence of an idiopathic disease in a patient with rheumatoid arthritis. Pityriasis rosea-like eruptions have long been a recognised complication of treatment with aurothiomalate. ${ }^{2}$ Our findings after rechallenging with gold confirm that they and rashes resembling discoid eczema are reactions to gold (auranofin and aurothiomalate). In all cases where it was performed, histology confirmed the clinical diagnosis. It is our impression that the pityriasiform reaction and discoid eczema are two ends of a spectrum. One patient initially developed pityriasis rosea which subsequently developed into discoid eczema. In addition, the histology of discoid eczema is a more florid form of that seen in pityriasis rosea. The finding of granular deposits of $\operatorname{IgM}$ was unexpected, though this has previously been reported to be a non-specific reaction $^{6}$ and not diagnostic, on its own, of cutaneous lupus erythematosus. Previous studies have found perivascular deposits of immunoreactants in normal rheumatoid skin. ${ }^{7}$

The lack of recurrence in one patient after the reintroduction of gold led us to suspect that the reaction might be related to the total accumulation of gold within the body with time, rather than an allergic mechanism, analogous to the pityriasiform reaction with captopril. ${ }^{5}$ Our subsequent findings support this idea. The negative prick and intradermal tests seem to exclude immediate type hypersensitivity as do the normal IgE levels and lack of any significant increase in eosinophil count. This contrasts with previous studies, ${ }^{34}$ in which the type of skin eruption was not specified, which found an increased eosinophil count and total IgE with cutaneous gold toxicity, though a subsequent study found no relation with total IgE. Additionally, the finding that patch and intradermal tests were negative and that lymphocyte proliferation to gold in patients was comparable with that in control sub;ects confirms earlier findings 9 that delayed type hypersensitivity does not play a part in cutaneous gold toxicity, though the type of reaction in this study was not specified. The observation that lymphocytes from some patients and control subjects reacted non-specifically with gold was interesting but of uncertain relevance.

If the rash had been allergic in nature it would be expected that the eruption would continue as long as treatment with gold was given. In seven patients, however, the rash was controlled with topical treatment without a reduction in gold dose and in a further three patients the rash was controlled by a reduction in dose or the frequency of gold treatment. Support for a possible dose related effect comes from the finding that gold can inhibit prostaglandin synthesis and two human epidermal enzymes in vitro. ${ }^{10}$ Topical steroids may antagonise a biochemical alteration induced by gold explaining why the rash resolved despite an unchanged gold dose. This is at variance with a previous study ${ }^{11}$ which found no relation between 'gold dermatitis' (type unspecified) and cutaneous gold levels in four patients. In three of our patients who did not respond to a topical steroid the rash resolved with continued treatment and a reduction in gold dose. In no patient did an exfoliative dermatitis develop despite continued treatment with gold.

The improvement in the erythrocyte sedimentation rate and levels of $\mathrm{C}$ reactive protein, which are associated with disease control, with the development of the pityriasiform and discoid eczematous reactions confirms earlier findings that gold associated skin rashes occur at a time when the arthritis is going into remission. ${ }^{12}$ We suggest that this occurs because the patient is adequately loaded with gold and that it is a dose related, not allergic, reaction which can generally be managed with topical treatment or a reduction in dose of gold.

In conclusion, we have reported 16 patients with a spectrum from pityriasiform to discoid 
eczematous response to treatment with gold. We suggest that this is related to the accumulation of gold within the body. If a treatment response is being obtained, gold can be continued with treatment of the skin rash initially with a potent topical steroid and, if this is ineffective, a reduction in the dose or frequency of gold administration.

1 Gibbons R B. Complications of chrysotherapy. Arch Intern Med 1979; 139: 343-6.

2 Pennys N S, Ackerman A B, Gottlieb N L. Gold dermatitis: a clinical and histopathological study. Arch Dermatol 1974; 109: 372-6.

3 Davis P, Hughes G R V. Significance of eosinophilia during gold therapy. Arthritis Rheum 1974; 17: 964-8.

4 Davis P, Ezeoke A, Munro J, Hobbs J R, Hughes G R V. Immunological studies on the mechanism of gold hypersensitivity reactions. $B M \mathcal{F}$ 1973; iii: 676-8.
5 Wilkin J K, Kirkendall W M. Pityriasis rosea-like rash from captopril. Arch Dermatol 1982; 118: 186-7.

6 Wojnarowska F, Bhogal B, Black M M. The significance of an IgM band at the dermo-epidermal junction. 7 Cutaneous Pathol 1986; 13: 359-62.

7 Fitzgerald O M, Barnes L, Woods R, McHugh L, Barry C, O'Loughlin S. Direct immunofluorescence of normal skin in rheumatoid arthritis. Br $\mathcal{F}$ Rheumatol 1985; 24: 340-5.

8 Grennan D M, Palmer D G. Serum IgE concentrations in rheumatoid arthritis: lack of correlation with gold toxicity. BMF 1979; ii: 1477-8.

9 Denman E J, Denman A M. The lymphocyte transformation test and gold hypersensitivity. Ann Rheum Dis 1968; 27: $582-9$.

10 Penneys N S, Ziboh V, Gottlieb N L, Katz S. Inhibition of prostaglandin synthesis and human epidermal enzymes by aurothiomalate in vitro: possible actions of gold in pemphigus. F Invest Dermatol 1974; 63: 356-61

11 Gottlieb N L, Smith P M, Penneys N S, Smith E M. Gold concentrations in hair, nail and skin during chrysotherapy. Arthritis Rheum 1974; 17: 56-62.

12 Caspi $D$, Tishler $M$, Yaron $M$. Association between gold induced skin rash and remission in patients with rheumatoid arthritis. Ann Rheum Dis 1989; 48: 730-2. 